\title{
Risk factors for progressive neuromuscular scoliosis requiring posterior spinal fusion after selective dorsal rhizotomy
}

\author{
${ }^{*}$ Vijay M. Ravindra, MD, MSPH, ${ }^{1}$ Michael T. Christensen, BS, ${ }^{1}$ Kaine Onwuzulike, MD, PhD, ${ }^{1}$ \\ John T. Smith, MD, ${ }^{2}$ Kyle Halvorson, MD, ${ }^{1}$ Douglas L. Brockmeyer, MD, ${ }^{1}$ Marion L. Walker, MD, ${ }^{1}$ and \\ Robert J. Bollo, MD1 \\ ${ }^{1}$ Division of Pediatric Neurosurgery, Department of Neurosurgery; and 2Division of Pediatric Orthopedic Surgery, Department of \\ Orthopedic Surgery, University of Utah School of Medicine, Salt Lake City, Utah
}

\begin{abstract}
OBJECTIVE Selective dorsal rhizotomy (SDR) via limited laminectomy is an effective treatment of lower-extremity spasticity in the pediatric population. Children with spasticity are also at risk for neuromuscular scoliosis; however, specific risk factors for progressive spinal deformity requiring posterior spinal fusion (PSF) after SDR are unknown. The authors' goal was to identify potential risk factors.
\end{abstract}

METHODS The authors performed a retrospective cohort study of patients who underwent SDR via limited laminectomy between 2003 and 2014 and who had at least 1 year of follow-up. They analyzed demographic, clinical, and radiographic variables to elucidate risk factors for progressive neuromuscular scoliosis. The primary outcome was need for PSF.

RESULTS One hundred thirty-four patients underwent SDR and had at least 12 months of follow-up (mean 65 months); 48 patients (36\%) had detailed pre- and postoperative radiographic data available. The mean age at surgery was 10 years (SD 5.1 years). Eighty-four patients (63\%) were ambulatory before SDR, 109 (82\%) underwent a single-level laminectomy, and a mean of $53 \%$ of the dorsal rootlets from L-1 to S-1 were sectioned. Fifteen patients (11.2\%) subsequently required PSF for progressive deformity. Nonambulatory status $(p<0.001)$ and a preoperative Cobb angle $>30^{\circ}(p=$ 0.003 ) were significantly associated with PSF on univariate analysis, but no statistically significant correlation was found with any clinical or radiographic variable and PSF after SDR on multivariate regression analysis.

CONCLUSIONS Patients with preoperative nonambulatory status and Cobb angle $>30^{\circ}$ may be at risk for progressive spinal deformity requiring PSF after SDR. These are well-known risk factors for progressive deformity in children with spasticity in general. Although our analysis suggests SDR via limited laminectomy may not significantly accelerate the development of neuromuscular scoliosis, further case-control studies are critical to elucidate the impact of SDR on spinal deformity.

https://thejns.org/doi/abs/10.3171/2017.5.PEDS16630

KEY WORDS selective dorsal rhizotomy; kyphosis; Cobb angle; spinal fusion; spine

$\mathrm{S}$ ELECTIVE dorsal rhizotomy (SDR) is a well-recognized surgical treatment for lower-extremity spasticity. Although it was classically used to treat diplegic spasticity in children with cerebral palsy, ${ }^{1}$ its indications have expanded to include application in children with spastic hemiplegia and hypoxic encephalopathy. ${ }^{12}$ The operation is performed at the level of the lumbosacral nerve roots to reduce spasticity in the lower limbs by interrupting the afferent input of the monosynaptic stretch reflex. ${ }^{11}$
The procedure was introduced in the 1970s by Fasano ${ }^{7-9}$ at the University of Torino and popularized by Peacock ${ }^{22-24}$ in the United States.

The procedure as performed by Peacock involved a multilevel laminectomy, typically from L-2 to L-5, to expose nerve roots where they exited the thecal sac. Barolat ${ }^{4}$ further described the Fasano technique as a limited exposure of the cauda equina, and this approach for SDR has become extremely common. At most centers, preoperative

ABBREVIATIONS GMFCS = Gross Motor Function Classification System; ITB = intrathecal baclofen; PSF = posterior spinal fusion; SDR = selective dorsal rhizotomy . SUBMITTED November 11, 2016. ACCEPTED May 23, 2017.

INCLUDE WHEN CITING Published online September 8, 2017; DOI: 10.3171/2017.5.PEDS16630.

* Dr. Ravindra and Mr. Christensen contributed equally to this work. 
MRI is performed to identify the vertebral level of the conus medullaris, and a limited laminectomy (usually at a single level, most commonly L-1) is performed. Progressive spinal deformity after SDR has been reported, including scoliosis, kyphosis, lordosis, lumbar spondylolysis, and spondylolisthesis. ${ }^{10,14}$ Children with spastic cerebral palsy are at higher risk for developing progressive scoliosis than other children, especially younger children with curves of higher magnitude. $2,16,26,27$

SDR performed via a large, multilevel laminectomy (L1-5) is clearly associated with an increased risk of progressive spinal deformity in children with cerebral palsy. ${ }^{30}$ Theoretically, SDR performed via a limited laminectomy is less likely to increase the risk or accelerate the progression of spinal deformity, but the impact of changes in muscle tone after rhizotomy in children with neuromuscular scoliosis remains poorly understood. Therefore, even a single-level laminectomy at the biomechanically important thoracolumbar junction may have an impact on deformity progression in a high-risk population. Unfortunately, specific clinical and radiographic risk factors for progressive spinal deformity requiring posterior spinal fusion (PSF) after SDR via limited laminectomy have yet to be definitively elucidated.

The aim of the current study was to identify specific clinical and radiographic risk factors that characterize patients with significant spinal deformity progression after SDR via a limited laminectomy and who ultimately required PSF. Identifying these patients before SDR is the critical first step in determining the impact of SDR on curve progression and optimizing treatment of spasticity in children with neuromuscular scoliosis.

\section{Methods \\ Study Population}

We performed a single-center retrospective cohort study of patients from a tertiary, Level 1 pediatric referral center. The study cohort included all children less than 18 years of age who underwent SDR via a limited laminectomy performed by two attending neurosurgeons (M.L.W. and R.J.B.) and who had at least 1 year of clinical and radiographic follow-up over a 12-year study period (20032014). Details of the surgical procedure, patient selection criteria, and intraoperative decision-making have been previously reported. ${ }^{19}$ Institutional review board approval was obtained prior to data collection. Patients who underwent SDR were identified by searching a prospectively collected neurosurgical database at Primary Children's Hospital.

\section{Data Collection}

After the study population was identified, data were abstracted from electronic medical records and imaging studies. Data collected included sex, etiology of spasticity (extreme prematurity and periventricular leukomalacia vs other, including perinatal stroke, hypoxic ischemic encephalopathy, and congenital migration anomalies), age at SDR, the Gross Motor Function Classification System (GMFCS), ${ }^{20}$ number of bony levels included in the laminectomy, overall percentage of rootlets cut, whether the procedure was a unilateral or bilateral rhizotomy, and preoperative ambulatory status defined as community ambulation with or without assistive device. Additional data recorded included history of intrathecal baclofen (ITB) use, the presence of a CSF shunt, and the duration of follow-up after SDR. Imaging characteristics included the level of the conus medullaris; the presence of syringomyelia, preand postoperative kyphosis, or lordosis; Cobb angle (see details below); and pelvic parameters including pelvic tilt, pelvic incidence, and sacral slope.

The primary outcome measure was the need for PSF to treat progressive neuromuscular scoliosis. The decision to offer PSF was based on the evaluation of a senior pediatric orthopedic spine surgeon (J.T.S.). Indications for PSF were accepted published criteria including progressive deformity, sitting balance, worsening pulmonary function, and worsening symptoms attributed to deformity (painful deformity or difficulty caring for the child). Indications for surgical correction included scoliosis that exceeded $45^{\circ}-$ $50^{\circ}$ in children 10 years of age or older, curve progression greater than $10^{\circ}$, or significant deterioration in the child's functionality. ${ }^{13,15,18}$ The aim of surgery in each case was to balance the spine and pelvis; restore trunk alignment; prevent progression of deformity; improve sitting/standing posture; improve walking ability; and prevent respiratory, feeding, and skin complications. ${ }^{3,18}$

\section{Radiographic Measurements}

Preoperative and postoperative spine radiographs were reviewed in all cases in which imaging studies were available. Angles for thoracolumbar scoliosis, thoracic kyphosis, and lumbar lordosis were measured on spine radiographs. The degree of scoliosis was measured using the Cobb technique, ${ }^{6}$ from the superior aspect and the inferior aspect of the vertebral bodies of the uppermost and lowermost vertebrae of the scoliotic curve, respectively. Kyphosis was measured from the superior aspect of T-5 to the inferior aspect of T-12 and lordosis from the superior surface of L-1 or L-2 to the inferior surface of L-5 also with the Cobb technique.

\section{Statistical Analysis}

The data were descriptively reported as means with standard deviations for continuous data and percentages for categorical data. We analyzed demographic, clinical, and pre- and postoperative radiographic variables to elucidate risk factors for progressive neuromuscular scoliosis associated with PSF in patients after SDR via limited laminectomy. An independent t-test was performed on all continuous variables to detect differences between groups. Significant results in the independent t-test (preoperative Cobb angle $\geq 30^{\circ}$, preoperative thoracic kyphosis $\geq 65^{\circ}$ ) were converted to ordinal variables to generate cutoffs to interpret the data in a more clinically relevant manner (Table 1).

Univariate analysis was performed to identify unadjusted risk factors for PSF using the chi-squared test for categorical variables and independent t-test for continuous variables. The Bonferroni correction was used to mitigate the possibility of Type 1 error. Because 15 variables ( 8 
TABLE 1. Basic clinical and demographic information and results of the univariate analysis of risk factors for patients who underwent SDR and developed progressive deformity requiring PSF

\begin{tabular}{|c|c|c|c|c|}
\hline Variable & All Patients $(n=134)$ & No Progressive Deformity $(n=119)$ & Deformity Requiring PSF $(n=15)$ & p Value \\
\hline \multicolumn{5}{|l|}{ Patient demographics } \\
\hline No. of patients & $134(100 \%)$ & $119(89 \%)$ & $15(11 \%)$ & NA \\
\hline Mean age $\pm S D$, yrs & $10.0 \pm 5.1$ & $10.0 \pm 5.3$ & $10.0 \pm 3.5$ & 0.985 \\
\hline Male sex & $78(65 \%)$ & $71(60 \%)$ & $7(46 \%)$ & 0.336 \\
\hline \multicolumn{5}{|l|}{ Clinical factors } \\
\hline Mean GMFCS score & 3.19 & 3.00 & 3.86 & 0.028 \\
\hline History ITB pump & $31(23 \%)$ & $22(18 \%)$ & $9(60 \%)$ & $<0.001$ \\
\hline History of VP shunt & $26(19 \%)$ & $21(18 \%)$ & $5(33 \%)$ & 0.148 \\
\hline Bilateral SDR & $107(80 \%)$ & $92(77 \%)$ & $15(100 \%)$ & 0.039 \\
\hline Etiology of spasticity (cerebral palsy) & $70(52 \%)$ & $62(52 \%)$ & $8(53 \%)$ & 0.928 \\
\hline Nonambulatory prior to SDR & $50(37 \%)$ & $36(30 \%)$ & $14(93 \%)$ & $<0.001$ \\
\hline Variable & All Patients $(n=79)$ & No Progressive Deformity $(n=65)$ & Deformity Requiring PSF $(n=15)$ & $\mathrm{p}$ Value \\
\hline \multicolumn{5}{|l|}{ Preop imaging factors } \\
\hline Presence of scoliosis & $58(73 \%)$ & $44(68 \%)$ & $15(100 \%)$ & 0.013 \\
\hline Cobb angle $>30^{\circ}$ & $19(24 \%)$ & $11(17 \%)$ & $8(53 \%)$ & 0.003 \\
\hline Thoracic kyphosis $>65^{\circ *}$ & $20(33 \%)$ & $12(60 \%)$ & $8(66 \%)$ & 0.006 \\
\hline Variable & All Patients & No Progressive Deformity & Deformity Requiring PSF & p Value \\
\hline \multicolumn{5}{|l|}{ Postop imaging factors } \\
\hline New scoliosis after op $†$ & $7(14 \%)$ & $7(19 \%)$ & $0(0 \%)$ & 0.086 \\
\hline Progression of $\mathrm{Cobb}$ angle $>20^{\circ} \dagger$ & $19(39 \%)$ & $10(29 \%)$ & $9(64 \%)$ & 0.020 \\
\hline Progression of kyphosis $>15^{\circ} \ddagger$ & $11(38 \%)$ & $7(35 \%)$ & $4(44 \%)$ & 0.628 \\
\hline Progression of lordosis $>10^{\circ} \ddagger$ & $14(48 \%)$ & $13(68 \%)$ & $1(10 \%)$ & 0.003 \\
\hline
\end{tabular}

$\mathrm{VP}=$ ventriculoperitoneal.

* Imaging studies available in 60 patients.

$\uparrow$ Imaging studies available in 49 patients.

$\ddagger$ Imaging studies available in 29 patients.

clinical and 7 radiographic) were analyzed, the corrected $p$ value to determine statistical significance was set at $\mathrm{p}=$ 0.003 . Subsequently, binary logistic regression was performed including all variables with $\mathrm{p}<0.20$ on univariate analysis on the 48 patients with detailed radiographic information. Statistical analysis was performed using SPSS version 24 (IBM).

\section{Results \\ Demographics}

A total of 153 patients underwent SDR via limited laminectomy during the study period from January 2003 to December 2014 (Fig. 1). Nineteen patients (12.4\%) had < 12 months of follow-up and were excluded from further analysis. Of the remaining 134 patients, 78 were male (58\%). One hundred nineteen patients (89\%) did not demonstrate progressive deformity requiring PSF, and 15 children underwent PSF for progressive neuromuscular scoliosis (Table 1). The mean age at SDR was 10 years (SD 5.1 years), and the mean clinical follow-up duration was 65 months (SD 36.2 months).

\section{Clinical and Surgical Information}

Among 134 patients, 31 had a history of ITB therapy, which was more prevalent in children with spinal defor- mity requiring PSF ( $18 \%$ vs $60 \%, \mathrm{p}<0.001)$. Twenty-six patients $(19 \%)$ had a history of hydrocephalus treated with a CSF shunt, with no significant difference between patients who did not require PSF and those who did (18\% vs $33 \%, \mathrm{p}=0.148)$. The mean GMFCS score for the entire cohort was 3.19. Patients who required PSF had a significantly higher GMFCS score (3.86) than those who did not (3.00; $\mathrm{p}=0.028$ ). Bilateral SDR was performed in $80 \%$ of patients, and $14 \%$ ultimately required PSF. Conversely, none of the patients who progressed to PSF underwent a unilateral SDR $(p=0.039)$. The etiology of spasticity was extreme prematurity with periventricular leukomalacia in nearly $50 \%$ of the patients in either group, compared with all other etiologies, including perinatal stroke, hypoxic ischemic encephalopathy, or congenital migration disorders (52\% vs $53 \%, \mathrm{p}=0.928)$. Eighty-four patients $(63 \%)$ were ambulatory and 50 (37\%) were nonambulatory before SDR. Preoperative nonambulatory status was a significant risk factor for PSF (30\% vs 93\%, p < 0.001). One hundred nine patients (82\%) had a single-level laminectomy at T-12 or L-1, with no difference between cohorts (Table 2). An average of 53\% (SD 9.2\%) of the dorsal rootlets were cut between L-1 and S-1, and the percentile of rootlets cut was not associated with PSF $(53 \%$ vs $57 \%, p=0.096)$. Fifteen patients $(11 \%)$ required PSF after SDR for neuromuscular scoliosis. Detailed preoperative images were available on 


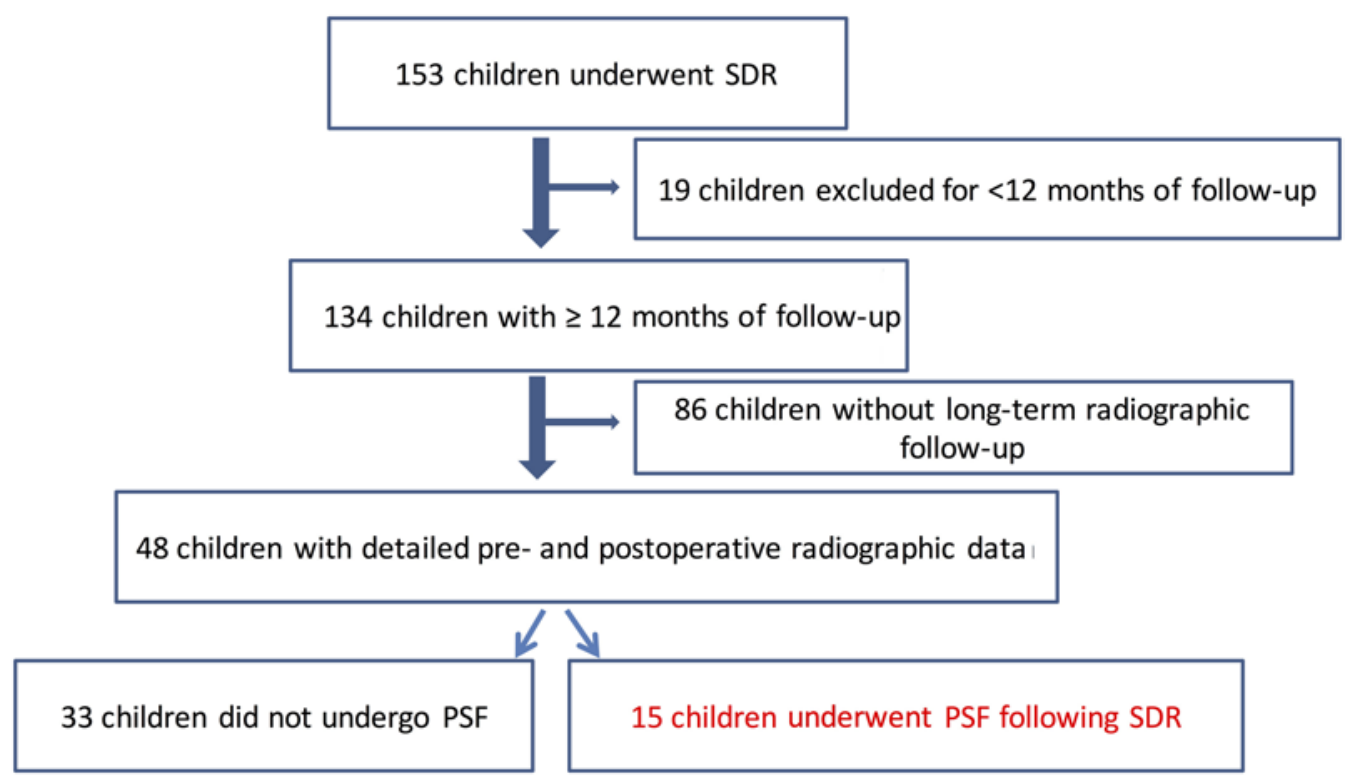

FIG. 1. Flow chart delineating the study population. Figure is available in color online only.

79 patients (59\%) and pre- and postoperative radiographic data on 48 patients (36\%). These patients served as the primary study group for further analysis of radiographic risk factors for PSF.

\section{Preoperative Imaging Factors}

Of 79 patients with adequate preoperative images, 58 (73\%) had preoperative scoliosis, with a prevalence of $68 \%$ in children in whom the deformity did not progress to a degree requiring PSF and $100 \%$ in those in whom it $\operatorname{did}(p=0.013)($ Table 1). The independent t-test revealed a

\section{TABLE 2. Summary of variables recorded}

\begin{tabular}{lccr}
\hline \multicolumn{1}{c}{ Variable } & $\begin{array}{c}\text { No } \\
\text { Progressive } \\
\text { Deformity }\end{array}$ & $\begin{array}{c}\text { Deformity } \\
\text { Requiring } \\
\text { PSF }\end{array}$ & $\begin{array}{c}\text { p } \\
\text { Value }\end{array}$ \\
\hline $\begin{array}{l}\text { Percentage of dorsal roots } \\
\text { cut }\end{array}$ & $52.51 \pm 9.2$ & $57.17 \pm 7.2$ & 0.096 \\
\hline $\begin{array}{l}\text { No. of levels for laminec- } \\
\text { tomy (SDR) }\end{array}$ & $1.2 \pm 0.556$ & $1.13 \pm 0.352$ & 0.422 \\
\hline Preop Cobb angle $\left(^{\circ}\right)$ & $15.45 \pm 19.6$ & $42.2 \pm 28$ & 0.003 \\
\hline Postop Cobb angle $\left(^{\circ}\right)$ & $23.91 \pm 20.73$ & $65 \pm 23.3$ & $<0.001$ \\
\hline Preop kyphosis angle $\left(^{\circ}\right)$ & $55.04 \pm 13.9$ & $74.67 \pm 19.97$ & $<0.001$ \\
\hline Postop kyphosis angle $\left(^{\circ}\right)$ & $58.5 \pm 23.48$ & $90.36 \pm 16.86$ & $<0.001$ \\
\hline Preop lordosis angle $\left(^{\circ}\right)$ & $34.4 \pm 10.9$ & $44.5 \pm 19.65$ & 0.083 \\
\hline Postop lordosis angle $\left(^{\circ}\right)$ & $45.65 \pm 24.38$ & $30.18 \pm 25.49$ & 0.082 \\
\hline Preop pelvic incidence $\left(^{\circ}\right)$ & $60.37 \pm 12.3$ & $64.6 \pm 14.03$ & 0.247 \\
\hline Postop pelvic incidence $\left(^{\circ}\right)$ & $51.19 \pm 17.52$ & $55.55 \pm 23.27$ & 0.520 \\
\hline Preop sacral slope $\left({ }^{\circ}\right)$ & $40.21 \pm 11.8$ & $39.47 \pm 13.7$ & 0.834 \\
\hline Postop sacral slope $\left({ }^{\circ}\right)$ & $38.84 \pm 19.3$ & $30.55 \pm 14.1$ & 0.202 \\
\hline Preop pelvic tilt $\left(^{\circ}\right)$ & $19.79 \pm 7.41$ & $26.27 \pm 12.23$ & 0.066 \\
\hline Postop pelvic tilt $\left({ }^{\circ}\right)$ & $17.3 \pm 14.67$ & $31.64 \pm 25.18$ & 0.028 \\
\hline
\end{tabular}

Continuous variables are presented as the mean $\pm \mathrm{SD}$. significant difference in preoperative Cobb angle between these two groups $\left(15.45^{\circ} \pm 19.6^{\circ}\right.$ [deformity requiring PSF] vs $42.2^{\circ} \pm 28^{\circ}$ [deformity not requiring PSF], respectively, $\mathrm{p}=0.003$ ). To establish thresholds, we converted this continuous variable into an ordinal variable for clinically meaningful use and interpretation. Of the 79 patients, 19 (24\%) had a preoperative Cobb angle $>30^{\circ}(17 \%$ vs $53 \%$, respectively; $\mathrm{p}=0.003$ ). The independent $\mathrm{t}$-test also revealed a significant difference in preoperative kyphosis angle between the two groups $\left(55.04^{\circ} \pm 13.9^{\circ}\right.$ [deformity requiring PSF] vs $74.67^{\circ} \pm 19.97^{\circ}$ [deformity not requiring PSF], $\mathrm{p}<0.001)$. Thirty-three percent of patients had evidence of preoperative thoracic kyphosis $>65^{\circ}(25 \%$ vs $67 \%$, respectively, $\mathrm{p}=0.006$ ). Preoperative lumbar lordosis angle, pelvic incidence, sacral slope, and pelvic tilt did not differ significantly between the two groups and were not included in the univariate analysis to establish clinically relevant cut-offs (Table 2 ).

\section{Postoperative Imaging Factors}

Among 48 patients with postoperative radiographic studies available for review, $7(14 \%)$ without preoperative coronal deformity developed new scoliosis after SDR, none of whom required PSF (19\% vs 0\%, $\mathrm{p}=0.086)$. The independent t-test revealed a significantly greater postoperative Cobb angle in patients who required PSF than in those who did not require it $\left(23.91^{\circ} \pm 20.73^{\circ}\right.$ vs $65^{\circ} \pm 23.3^{\circ}$, $\mathrm{p}<0.001$ ). Thus, we converted this continuous variable into an ordinal variable for clinically meaningful use and interpretation, and we discovered that of the 48 patients, $19(40 \%)$ had a progression of Cobb angle $>20^{\circ}(29 \%$ vs $64 \%, \mathrm{p}=0.020$ ). The independent t-test also revealed a significant difference in postoperative thoracic kyphosis after SDR $\left(58.5^{\circ} \pm 23.48^{\circ}\right.$ vs $\left.90.36^{\circ} \pm 16.86^{\circ}, \mathrm{p}<0.001\right)$. Thirty-eight percent of patients had progression of kyphosis $>15^{\circ}(35 \%$ vs $44 \%, p=0.628)$. Finally, the independent $\mathrm{t}$-test demonstrated a difference in postoperative lordosis 
TABLE 3. Binary logistic regression model created including all variables for which the $p$ value was $<0.20$ on univariate analysis of the 48 patients with detailed radiographic information*

\begin{tabular}{llc}
\hline \multicolumn{1}{c}{ Variable } & Score & p Value \\
\hline ITB pump & 1.00 & 0.317 \\
\hline Bilateral SDR & 0.529 & 0.467 \\
\hline Nonambulatory prior to SDR & 2.571 & 0.109 \\
\hline Percentage of dorsal roots cut & 0.047 & 0.829 \\
\hline New scoliosis postop & 1.8 & 0.180 \\
\hline Preop Cobb angle $>30^{\circ}$ & 0.112 & 0.737 \\
\hline$>20^{\circ}$ progression of Cobb angle & 1.80 & 0.180 \\
\hline Preop thoracic kyphosis $>65^{\circ}$ & 1.125 & 0.289 \\
\hline$>10^{\circ}$ progression of lordosis $\dagger$ & 9.0 & 0.003 \\
\hline * Significance for model was 0.043. & \\
$\dagger$ The progression of lumbar lordosis $>10^{\circ}$ in children who did not require PSF \\
likely represents a finding in the setting of small sample size.
\end{tabular}

angle $\left(45.65^{\circ} \pm 24.38^{\circ}\right.$ vs $\left.30.18^{\circ} \pm 25.49^{\circ}, \mathrm{p}<0.082\right)$. Of the 29 patients with pre- and postoperative images available to assess for change in lordosis before and after SDR, $14(48 \%)$ had progression of lordosis $>10^{\circ}$; however, this was more prevalent in the cohort that did not require PSF (68\% vs $10 \%, p=0.003)$. No patients experienced progressive lumbar spondylolysis or spondylolisthesis.

\section{Multivariate Analysis}

The univariate analysis demonstrated only two preoperative variables were significantly associated with PSF after SDR when Bonferroni correction was applied: nonambulatory status $(\mathrm{p}<0.001)$ and preoperative Cobb angle $>30^{\circ}(\mathrm{p}=0.003)$. A binary logistic regression model was created including all variables for which the $\mathrm{p}$ value was $<$ 0.20 in univariate analysis of the 48 patients with detailed radiographic information. This, however, did not yield any variables independently associated with PSF (Table 3).

\section{Discussion}

In this study, we demonstrated that only nonambulatory status and preoperative Cobb angle $>30^{\circ}$ were associated with a need for PSF after SDR in the univariate analysis, and no variables were independently associated with PSF after SDR in the multivariable analysis. These clinical and radiographic factors are well known for children with cerebral palsy and spasticity, regardless of SDR (Fig. 2). We did not identify any variables that clearly modify the risk of progressive neuromuscular scoliosis in patients undergoing SDR via limited laminectomy.

\section{The Natural History of Spinal Deformities in Cerebral Palsy}

Children with spastic cerebral palsy are at higher risk for neuromuscular scoliosis and progressive spinal deformity than those without this condition., 2,16,26,27 Progressive neuromuscular scoliosis occurs in children with cerebral palsy, and the incidence and degree of severity vary. Curves greater than $10^{\circ}$ are seen in $21 \%-64 \%, 2,16,26,27$ whereas curves greater than $30^{\circ}$ are seen in $6 \%-14 \%$ of
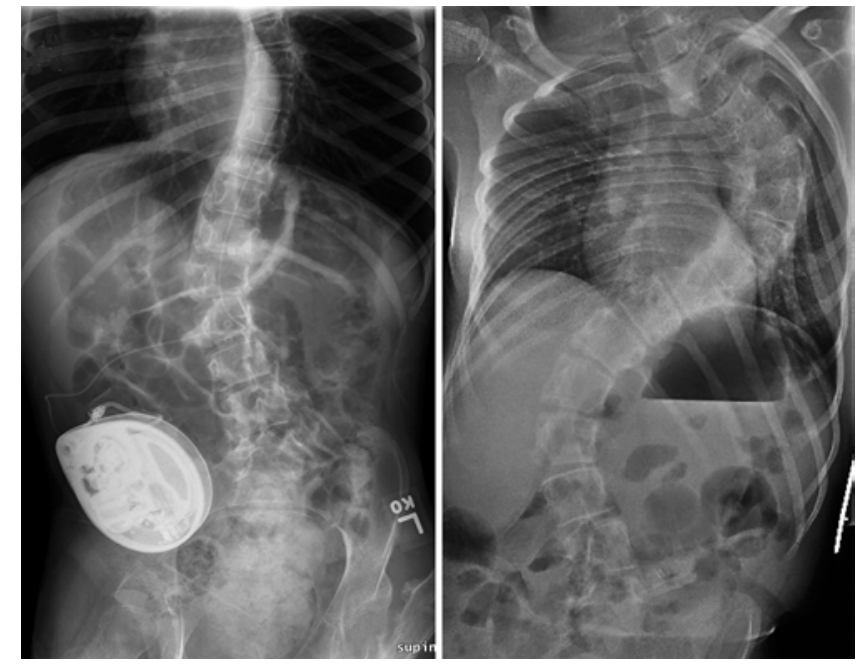

FIG. 2. Radiographs obtained in a female patient with spastic quadriparesis in the context of schizencephaly who underwent SDR via an L-1 laminectomy when she was 4 years of age. Prior to SDR, her spasticity was managed via ITB therapy. She was weaned off baclofen prior to SDR, and the pump and catheter were removed at the same time. She was nonambulatory prior to SDR, with a preoperative levoscoliosis and a Cobb angle of $38^{\circ}$ (left). Two years after SDR, she developed significant progression of her scoliotic curve, with a Cobb angle $>100^{\circ}$ (right).

patients. ${ }^{2,5}$ In a series of 37 patients, Saito and colleagues ${ }^{29}$ discovered that scoliosis started to progress at 10 years of age and rapidly progressed during preadolescence and puberty. With a mean follow-up duration of nearly 17 years, they found the mean magnitude of the curve to be $55^{\circ} .{ }^{29} \mathrm{In}$ children with a spinal curve $>40^{\circ}$ seen before the age of 15 years, scoliosis progressed to $>60^{\circ}$ in $85 \%$ of patients, whereas in children with curves $<40^{\circ}$ at 15 years, scoliosis only progressed to $>60^{\circ}$ in $13 \%$. They also found that severe scoliosis defined by curves $>60^{\circ}$ was associated with total body involvement (67\%), bedridden status $(100 \%)$, and thoracolumbar curve (57\%). ${ }^{29}$ In contrast with patients with juvenile idiopathic scoliosis, patients with cerebral palsy may continue to have progression of their curvature even after they achieve skeletal maturation. ${ }^{17,31}$ In the aforementioned studies, however, neither did they discuss the incidence of scoliosis in relation to the presence of SDR, nor did they consider the potential role this procedure might have in deformity progression. Factors identified in our population that may be associated with progressive spinal deformity are similar to those described above (i.e., nonambulatory status, greater preoperative deformity, and deformity progression).

\section{SDR via Multilevel Laminectomy}

Historically, SDR has been performed via multilevel laminectomy or laminoplasty involving as many as 6 levels. ${ }^{30}$ The risk of progressive spinal deformity is likely increased after multilevel laminectomy. Yasuoka et al. ${ }^{33}$ identified a significant risk of kyphosis and kyphoscoliosis in children with cerebral palsy after undergoing SDR via multilevel laminectomy. Notably, they found that the younger the patient and the more cephalad the superior extent of the laminectomy, the higher was the likelihood of developing progressive spinal deformity. 
TABLE 4. Large series of patients undergoing SDR and the incidence of spinal deformity

\begin{tabular}{lcccccc}
\hline \multicolumn{1}{c}{ Authors \& Year } & $\begin{array}{c}\text { No. of } \\
\text { Patients }\end{array}$ & $\begin{array}{c}\text { Scoliosis } \\
(\%)\end{array}$ & $\begin{array}{c}\text { Kyphosis } \\
(\%)\end{array}$ & $\begin{array}{c}\text { Lordosis } \\
(\%)\end{array}$ & $\begin{array}{c}\text { Spondylolysis/ } \\
\text { Spondylolisthesis (\%) }\end{array}$ & $\begin{array}{c}\text { No. of Patients Requiring } \\
\text { Fusion/Correction }\end{array}$ \\
\hline Peter et al., 1990 & 55 & 16 & 5 & 7 & 9 & Not reported \\
\hline Turi \& Kalen, 2000 & 47 & 32 & 11 & 15 & Not reported & 3 \\
\hline Steinbok et al., 2005 & 105 & 54.8 & 38.6 & 21.3 & Not reported & 2 \\
\hline Johnson et al., 2004 & 34 & 24 & 5.8 & 50 & 18 & 0 \\
\hline Present study & 48 & 14 & 38 & 48 & 0 & 15 \\
\hline
\end{tabular}

In 1990, Peter et al. ${ }^{25}$ examined the incidence of spinal deformity in children after multilevel laminectomy for SDR. They observed scoliosis of $>10^{\circ}$ in $16 \%$, kyphosis in $5 \%$, lordosis in $7 \%$, and spondylolysis and/or spondylolisthesis in $9 \%$ of children in a group of patients undergoing multilevel laminectomy. They concluded that this degree of scoliosis, kyphosis, and lordosis was not greater than what would be expected in patients with spastic cerebral palsy without laminectomy. ${ }^{25}$ Conversely, in a series of 47 patients, Turi and Kalen ${ }^{32}$ found a $32 \%$ incidence of new spinal deformity 5 years after multilevel laminectomy for SDR (Table 4). The higher incidence seen in their series, as in ours, may reflect the severity of spasticity and cerebral palsy in the study population.

In a cohort of 34 ambulatory patients with spastic diplegia, Johnson et al. ${ }^{14}$ identified 20 new spinal deformities $(59 \%)$ at 5-11.6 years after SDR. Steinbok et al. ${ }^{30}$ observed that there was a lower incidence of scoliosis developing after SDR and a lower incidence of scoliosis progression greater than $10^{\circ}$ among children who walked or moved by commando crawling preoperatively. In the current study, nonambulatory status preoperatively was significantly associated with the need for PSF. This may be because children sitting in a wheelchair have worse spasticity and less paraspinal muscular support and, therefore, may be at higher risk for structural destabilization after SDR than children who are ambulatory. ${ }^{30}$

Steinbok et al. ${ }^{30}$ reviewed data collected from 105 patients who underwent SDR performed via multilevel laminectomy or laminoplasty; the patients were children with spastic cerebral palsy. The authors found a $54.8 \%$ prevalence of scoliosis at last follow-up, with $25 \%$ of the patients having a curvature that had worsened by $\geq 10^{\circ}$. In addition, the incidence of abnormal kyphosis was $38.6 \%$, with nearly $32 \%$ of the patients having worsening of $\geq 15^{\circ}$. The incidence of hyperlordosis was $21.3 \%$, with $36 \%$ of the patients having an increase in lordosis of $\geq 15^{\circ}$. In the current study, we chose to measure deformity progression according to whether PSF was necessary for curvature correction. The clinical relevance of progressive asymptomatic or minimally symptomatic deformity not severe enough to require intervention is challenging to interpret.

\section{SDR via Limited Laminectomy}

In the present study, we focused on patients who underwent a limited thoracolumbar laminectomy (T12-L2) and SDR. For this specific procedure, there are no other reports of studies of the need for PSF after SDR. Given the high risk of progressive neuromuscular scoliosis in chil- dren undergoing rhizotomy, even those who undergo SDR performed through a one- or two-level laminectomy at the biomechanically important thoracolumbar junction might have a higher risk of deformity over time compared with similar patients who did not undergo surgery. The additional change in muscle tone in the hips and lower extremities due to the SDR itself might also play an important role in the development or progression of spinal deformity. ${ }^{30}$ An alternative explanation, however, is that these children may have more severe spasticity at baseline. As stated previously, we did not identify any unique clinical or radiographic variables that clearly increased the risk of progressive deformity after SDR via limited laminectomy.

Papagelopoulos et al. ${ }^{21}$ reported on 36 patients who underwent lumbar or thoracolumbar laminectomy and found a $16.6 \%$ rate of spinal deformity, with 3 patients requiring fusion surgery for correction. These investigators found that the incidence of spinal deformity was increased in patients in whom more than two laminae were removed $(p<0.01)$ or a facetectomy was performed at the time of the initial operation $(\mathrm{p}<0.05)$. Using a cohort of $15 \mathrm{pa}-$ tients who underwent laminectomy in the thoracic-thoracolumbar region for intramedullary tumors, 9 of whom had worsened spinal alignment after surgery $(60 \%)$, Yeh et al. ${ }^{34}$ determined that laminectomy was associated with an increased risk of kyphosis $(p=0.01)$ and concluded that spinal sagittal malalignment after laminectomy or laminoplasty and the need for spinal fusion is more common in the thoracolumbar region versus the cervical-cervicothoracic region. They also reported a significantly lower incidence of spinal deformity after laminoplasty compared with laminectomy, although progressive spinal deformity did occur. In our cohort study, no patients underwent laminoplasty given the limited exposure needed to accomplish the procedure.

\section{Study Limitations}

There are several limitations of this study. The retrospective design is inherently limited by the information available in the electronic medical record and paper charts. For a study with emphasis on radiographic alignment parameters, this limitation is most pronounced because of the lack of complete preoperative and postoperative radiographic follow-up studies for all patients. In addition, although the univariate analysis demonstrated the significance of two well-described risk factors for progressive deformity in this population, no variables retained significance after multivariate analysis. This may be due to a relatively small number of patients with the primary outcome 
and thus would require a larger sample size. In addition, the progression of neuromuscular scoliosis in children undergoing SDR is likely to be multifactorial, and the study population is heterogeneous, including patients with spastic diplegia, spastic hemiparesis, and spastic quadriparesis. Specifically, $60 \%$ of patients who required PSF had previous spasticity reduction with ITB, which may accelerate spinal deformity in children with spasticity. ${ }^{6,28} \mathrm{~A}$ valid analysis of only children without a history of ITB therapy was not feasible because of sample size.

Although no independent risk factors were identified, it remains possible that SDR via a limited laminectomy accelerates progressive spinal deformity in some children. It is possible that patients in whom the scoliotic curve progressed received serial follow-up, thus potentially biasing the results and cutoffs for Cobb angle, kyphosis, and lordosis risk factors for higher parameters than could be seen if the entire population of children had had detailed radiographic follow-up after SDR. Additional consideration for the threshold of performing corrective surgery with PSF should be given. The experience reported reflects the practice patterns of one senior pediatric spinal deformity surgeon (J.T.S.) at a single metropolitan tertiary referral center, but patterns may vary among large academic medical centers. The evaluation of patients, treatment, and practice patterns is not standardized, and treatment decisions are made on a case-by-case basis, often by multidisciplinary teams. Further larger, case-control studies are needed to obtain full radiological profiles on all patients and compare data for patients with spasticity who undergo SDR with those for patients who do not undergo SDR to assess the true impact of SDR on spinal deformity in these children. There is a subset of children that may be predisposed to progression because of currently unknown or confounding factors, which may include individual vulnerability due to genetic or other factors, either with or without treatment of spasticity.

\section{Conclusions}

Only nonambulatory status and a preoperative Cobb angle $>30^{\circ}$, known risk-factors for progressive spinal deformity in children with cerebral palsy, were associated with a need for PSF in univariate analysis, and multivariate regression did not demonstrate any specific risk factors for PSF. Although these results suggest that SDR via limited laminectomy may not increase the risk of progressive spinal deformity in this population, more detailed radiographic information from a larger patient cohort, as well as prospective case-control studies of children with spasticity with and without SDR, are required to further elucidate if and how SDR may alter the natural history of progressive deformity in this population.

\section{References}

1. Abbott R, Forem SL, Johann M: Selective posterior rhizotomy for the treatment of spasticity: a review. Childs Nerv Syst 5:337-346, 1989

2. Balmer GA, MacEwen GD: The incidence and treatment of scoliosis in cerebral palsy. J Bone Joint Surg Br 52:134137,1970

3. Banta JV, Drummond DS, Ferguson RL: The treatment of neuromuscular scoliosis. Instr Course Lect 48:551-562, 1999

4. Barolat G: Dorsal selective rhizotomy through a limited exposure of the cauda equina at L-1. Technical note. J Neurosurg 75:804-807, 1991

5. Bonnett C, Brown JC, Grow T: Thoracolumbar scoliosis in cerebral palsy. Results of surgical treatment. J Bone Joint Surg Am 58:328-336, 1976

6. Burn SC, Zeller R, Drake JM: Do baclofen pumps influence the development of scoliosis in children? J Neurosurg Pediatr 5:195-199, 2010

7. Fasano VA, Barolat-Romana G, Ivaldi A, Sguazzi A: [Functional posterior radiculotomy, in the treatment of cerebral spasticity. peroperative electric stimulation of posterior roots and its use in the choice of the roots to be sectioned.] Neurochirurgie 22:23-34, 1976 (Fr)

8. Fasano VA, Barolat-Romana G, Zeme S, Squazzi A: Electrophysiological assessment of spinal circuits in spasticity by direct dorsal root stimulation. Neurosurgery 4:146-151, 1979

9. Fasano VA, Broggi G, Barolat-Romana G, Sguazzi A: Surgical treatment of spasticity in cerebral palsy. Childs Brain 4:289-305, 1978

10. Greene WB, Dietz FR, Goldberg MJ, Gross RH, Miller F, Sussman MD: Rapid progression of hip subluxation in cerebral palsy after selective posterior rhizotomy. J Pediatr Orthop 11:494-497, 1991

11. Grunt S, Fieggen AG, Vermeulen RJ, Becher JG, Langerak NG: Selection criteria for selective dorsal rhizotomy in children with spastic cerebral palsy: a systematic review of the literature. Dev Med Child Neurol 56:302-312, 2014

12. Gump WC, Mutchnick IS, Moriarty TM: Selective dorsal rhizotomy for spasticity not associated with cerebral palsy: reconsideration of surgical inclusion criteria. Neurosurg Focus 35(5):E6, 2013

13. Herring JA: Disorders of the brain, in Herring JA (ed): Tachdjian's Pediatric Orthopaedics. Philadelphia: WB Saunders, 2002, pp 1121-1248

14. Johnson MB, Goldstein L, Thomas SS, Piatt J, Aiona M, Sussman M: Spinal deformity after selective dorsal rhizotomy in ambulatory patients with cerebral palsy. J Pediatr Orthop 24:529-536, 2004

15. Lonstein JE, Akbarnia A: Operative treatment of spinal deformities in patients with cerebral palsy or mental retardation. An analysis of one hundred and seven cases. J Bone Joint Surg Am 65:43-55, 1983

16. Madigan RR, Wallace SL: Scoliosis in the institutionalized cerebral palsy population. Spine (Phila Pa 1976) 6:583-590, 1981

17. Majd ME, Muldowny DS, Holt RT: Natural history of scoliosis in the institutionalized adult cerebral palsy population. Spine (Phila Pa 1976) 22:1461-1466, 1997

18. McCarthy RE: Management of neuromuscular scoliosis. Orthop Clin North Am 30:435-449, viii, 1999

19. Oki A, Oberg W, Siebert B, Plante D, Walker ML, Gooch JL: Selective dorsal rhizotomy in children with spastic hemiparesis. J Neurosurg Pediatr 6:353-358, 2010

20. Palisano R, Rosenbaum P, Walters S, Russell D, Wood E, Galuppi B: Development and reliability of a system to classify gross motor function in children with cerebral palsy. Dev Med Child Neurol 39:214-223, 1997

21. Papagelopoulos PJ, Peterson HA, Ebersold MJ, Emmanuel PR, Choudhury SN, Quast LM: Spinal column deformity and instability after lumbar or thoracolumbar laminectomy for intraspinal tumors in children and young adults. Spine (Phila Pa 1976) 22:442-451, 1997

22. Peacock WJ, Arens LJ: Selective posterior rhizotomy for the relief of spasticity in cerebral palsy. S Afr Med J 62:119124, 1982 
23. Peacock WJ, Arens LJ, Berman B: Cerebral palsy spasticity. Selective posterior rhizotomy. Pediatr Neurosci 13:61-66, 1987

24. Peacock WJ, Staudt L: Selective posterior rhizotomy: history and results. Neurosurg State Art Rev 4:403-408, 1989

25. Peter JC, Hoffman EB, Arens LJ, Peacock WJ: Incidence of spinal deformity in children after multiple level laminectomy for selective posterior rhizotomy. Childs Nerv Syst 6:30-32, 1990

26. Robson P: The prevalence of scoliosis in adolescents and young adults with cerebral palsy. Dev Med Child Neurol 10:447-452, 1968

27. Rosenthal RK, Levine DB, McCarver CL: The occurrence of scoliosis in cerebral palsy. Dev Med Child Neurol 16:664667, 1974

28. Rushton PR, Nasto LA, Aujla RK, Ammar A, Grevitt MP, Vloeberghs MH: Intrathecal baclofen pumps do not accelerate progression of scoliosis in quadriplegic spastic cerebral palsy. Eur Spine J 26:1652-1657, 2017

29. Saito N, Ebara S, Ohotsuka K, Kumeta H, Takaoka K: Natural history of scoliosis in spastic cerebral palsy. Lancet 351:1687-1692, 1998

30. Steinbok P, Hicdonmez T, Sawatzky B, Beauchamp R, Wickenheiser D: Spinal deformities after selective dorsal rhizotomy for spastic cerebral palsy. J Neurosurg 102 (4 Suppl):363-373, 2005

31. Thometz JG, Simon SR: Progression of scoliosis after skeletal maturity in institutionalized adults who have cerebral palsy. J Bone Joint Surg Am 70:1290-1296, 1988
32. Turi M, Kalen V: The risk of spinal deformity after selective dorsal rhizotomy. J Pediatr Orthop 20:104-107, 2000

33. Yasuoka S, Peterson HA, MacCarty CS: Incidence of spinal column deformity after multilevel laminectomy in children and adults. J Neurosurg 57:441-445, 1982

34. Yeh JS, Sgouros S, Walsh AR, Hockley AD: Spinal sagittal malalignment following surgery for primary intramedullary tumours in children. Pediatr Neurosurg 35:318-324, 2001

\section{Disclosures}

Dr. Smith reports being a consultant for Globus, DePuy-Synthes, NuVasive, and Spineguard. He receives royalties from VEPTR 2 and is on the board of directors of the Children's Spine Foundation.

\section{Author Contributions}

Conception and design: Bollo. Acquisition of data: Christensen. Analysis and interpretation of data: Bollo. Drafting the article: Bollo, Ravindra. Critically revising the article: Ravindra, Christensen, Onwuzulike, Smith, Halvorson, Brockmeyer, Walker. Reviewed submitted version of manuscript: all authors. Approved the final version of the manuscript on behalf of all authors: Bollo.

\section{Correspondence}

Robert J. Bollo, Division of Pediatric Neurosurgery, Primary Children's Hospital, 100 North Mario Capecchi Dr., Ste. 3850, Salt Lake City, UT 84113. email: neuropub@hsc.utah.edu. 